\title{
Gambaran Temporomandibular Disorder pada Lanjut Usia melalui Fonseca's Questionnaire
}

\author{
Yosi Impiani, ${ }^{1}$ Dwi Ngestiningsih, ${ }^{2}$ Ira A. Kusuma ${ }^{1 *}$
}

\author{
${ }^{1}$ Departemen Kedokteran Gigi Fakultas Kedokteran Universitas Diponegoro, Semarang, Jawa \\ Tengah, Indonesia \\ ${ }^{2}$ Divisi Geriatri Bagian Ilmu Penyakit Dalam RSUP Kariadi, Semarang, Jawa Tengah, \\ Indonesia \\ Email korespondensi: iraanggarkusuma@gmail.com
}

\begin{abstract}
Decrease of stomatognathic organ function could result in decrease of quality of life (QoL) in geriatric patients. Temporomandibular disorder (TMD) creates a limitation in mouth opening, crepitation, and headache. This study was aimed to obtain the signs and symptoms of TMD through Fonseca's Questionnaire in Semarang nursing home for elderly. This was a descriptive and observational study with a cross sectional design. Fonseca's questionnaire and other questionnaires about medical history as well as dental and oral treatment history were used in this study. Fonseca anamnestic index was used to classify the TMD severity based on the total score of the answers. The chi-square was used to determine the differences between variables related to the TMD severity. The results obtained 57 respondents who were grouped based on age, sex, medical history, and dental and oral treatment history. There were 17 respondents without TMD, 18 had mild TMD, 12 had moderate TMD, and 10 had severe TMD. Besides age, emotional stress and tooth extraction were the most common causes and had significant effect on TMD severity ( $\mathrm{p}<0.05)$. In conclusion, TMD severity will increase along with age, meanwhile, optimal dental and medical care can help to reduce the TMD severity in geriatric patients.
\end{abstract}

Keywords: elderly, temporomandibular disorder, Fonseca's questionnaire

\begin{abstract}
Abstrak: Penurunan fungsi stomatognatik dapat menyebabkan penurunan kualitas hidup pada lansia. Penurunan fungsi tersebut pada temporomandibular disease (TMD) menyebabkan terjadinya keterbatasan dalam membuka mulut, krepitasi pada saat membuka atau menutup mulut, dan sakit kepala. Penelitian ini bertujuan untuk mendapatkan gambaran deteksi tanda dan gejala TMD melalui Fonseca's Questionnaire di panti wreda Kota Semarang. Jenis penelitian ialah deskriptif observasional dengan desain potong lintang menggunakan Fonseca's questionnaire serta kuesioner tentang riwayat medis, dan riwayat perawatan gigi dan mulut. Fonseca anamnestic index digunakan untuk menglasifikasikan tingkat keparahan TMD berdasarkan total skor jawaban kuesioner. Uji chisquare digunakan untuk mengetahui perbedaan antara variabel dengan tingkat keparahan TMD. Hasil penelitian mendapatkan 57 responden yang dikelompokkan berdasarkan usia, jenis kelamin, serta riwayat medis dan riwayat perawatan gigi dan mulut. Terdapat 17 responden tanpa TMD, 18 dengan TMD ringan, 12 dengan TMD sedang, dan 10 dengan TMD berat. Stres emosional dan pencabutan gigi merupakan penyebab tersering serta memiliki perbedaan bermakna pada tingkat keparahan TMD disamping usia $(\mathrm{p}<0,05)$. Simpulan penelitian ini ialah tingkat keparahan TMD akan meningkat seiring bertambahnya usia, namun perawatan medis serta gigi, dan mulut yang optimal dapat mengurangi keparahan TMD pada lansia.
\end{abstract}

Kata kunci: lanjut usia (lansia), temporomandibular disorder (TMD), Fonseca's questionnaire

\section{PENDAHULUAN}

Lanjut usia (lansia) merupakan tahap akhir perkembangan dari kehidupan manu- sia, ${ }^{1}$ yang ditandai dengan adanya penurunan kondisi fisik maupun sehingga berpotensi menimbulkan masalah kesehatan secara 
umum, termasuk degenerasi kesehatan gigi dan mulut. ${ }^{2}$ Proses degenerasi stomatognatik dalam lansia antara lain hilangnya jumlah gigi anterior maupun posterior akibat kelainan jaringan periodontal atau karies, hiposalivasi, penurunan aktivitas dan massa otot, serta terjadi penurunan fungsi pada temporomandibular joint (TMJ). ${ }^{3}$ Hal ini dapat mengakibatkan terjadinya temporomandibular disorder (TMD). ${ }^{1}$ Tanda dan gejala utama TMD ialah rasa nyeri pada TMJ, keterbatasan dalam membuka mulut, krepitasi pada saat membuka atau menutup mulut, dan sakit kepala. ${ }^{4}$

Salah satu cara pemeriksaan TMD ialah dengan menggunakan kuesioner yang berisi daftar tanda klinis dari TMD seperti pada Fonseca's Questionnaire (FQ). ${ }^{5}$ Kuesioner FQ terdiri dari 10 pertanyaan umum yang digunakan untuk mendeteksi tanda dan gejala TMD serta menglasifikasikan tingkat keparahan TMD berdasarkan keluhan yang dirasakan oleh penderita. ${ }^{6}$

Sejak tahun 1990 hingga 2025, Indonesia diperkirakan akan mengalami peningkatan terbesar dalam jumlah lansia. ${ }^{7}$ Seiring dengan besarnya peningkatan jumlah tersebut, diharapkan kualitas hidup lansia akan tetap optimal Oleh karena itu, diperlukan suatu studi tentang gambaran TMD pada lansia termasuk tanda dan gejalanya. Tujuan penelitian ini ialah untuk mendapatkan gambaran jumlah lansia penderita TMD di panti wreda Kota Semarang dengan menggunakan metode FQ.

\section{METODE PENELITIAN}

Penelitian ini dilakukan terhadap lansia berusia 60-92 tahun di Panti Wreda Pucang Gading Kota Semarang. Jenis penelitian ialah deskriptif observasional dengan desain potong lintang. Pengambilan sampel menggunakan metode purposive sampling.

Terdapat 57 lansia berusia 60-92 Tahun di Panti Wreda Pucang Gading Kota Semarang yang bersedia mengikuti kegiatan dan mematuhi instruksi yang diberikan serta mampu mendengar dan berkomunikasi dengan baik. Lansia dalam kondisi sakit akut, sedang menjalani perawatan TMD, memiliki gangguan sistem stomatognatik, demensia dan/atau penyakit Alzheimer, serta tidak berada di lokasi ketika penelitian berlangsung tidak diikutkan dalam pengambilan data.

Responden diminta untuk mengisi informed consent, lembar FQ (Tabel 1), ${ }^{8}$ serta lembar riwayat medis dan riwayat perawatan gigi dan mulut (Tabel 2). Responden diminta untuk mengisi salah satu jawaban antara ya, tidak, dan kadangkadang. Setiap jawaban "ya" diberi skor 10, jawaban "kadang-kadang" diberi skor 5, dan jawaban "tidak" diberi skor 0. Total skor dari 10 pertanyaan diklasifikasikan berdasarkan tingkat keparahan TMD pada Tabel $3{ }^{8}$

Tabel 1. Fonseca's questionnaire yang mendeskripsikan tanda klinis dari TMD ${ }^{8}$

\begin{tabular}{|c|c|c|c|c|}
\hline $\begin{array}{c}\text { No. } \\
1 .\end{array}$ & $\begin{array}{c}\text { Pertanyaan } \\
\text { Apakah Anda merasa kesulitan saat membuka mulut? }\end{array}$ & Ya & Kadang & Tidak \\
\hline 2. & $\begin{array}{l}\text { Apakah Anda merasa kesulitan saat memindahkan } \\
\text { rahang bawah dari sisi ke sisi? }\end{array}$ & & & \\
\hline 3. & Apakah Anda merasa lelah/otot sakit saat mengunyah? & & & \\
\hline 4. & Apakah Anda sering sakit kepala? & & & \\
\hline 5. & $\begin{array}{l}\text { Apakah Anda merasa sakit pada tengkuk atau leher } \\
\text { yang kaku? }\end{array}$ & & & \\
\hline 6. & $\begin{array}{l}\text { Apakah Anda pernah sakit telinga atau sakit pada sendi } \\
\text { cranio-mandibular }\end{array}$ & & & \\
\hline 7. & $\begin{array}{l}\text { Pernahkah Anda memperhatikan adanya bunyi klik } \\
\text { pada TMJ ketika mengunyah atau membuka mulut? }\end{array}$ & & & \\
\hline 8. & Apakah Anda sering mengeretakan gigi? & & & \\
\hline 9. & $\begin{array}{l}\text { Apakah Anda merasa gigi Anda tidak berartikulasi/ } \\
\text { oklusi dengan baik? }\end{array}$ & & & \\
\hline 10. & Apakah Anda merasa Anda orang yang tegang/gugup? & & & \\
\hline
\end{tabular}


Tabel 2. Riwayat medis dan riwayat perawatan gigi dan mulut

\begin{tabular}{|c|c|c|}
\hline No. & Riwayat & Ya \\
\hline 1. & Arthritis & \\
\hline 2. & $\begin{array}{l}\text { Gangguan muskulo- } \\
\text { skeletal di area kepala } \\
\text { dan leher }\end{array}$ & \\
\hline 3. & Stres emosional & \\
\hline 4. & Perawatan ortodontik & \\
\hline 5. & $\begin{array}{l}\text { Pemasangan crowns dan } \\
\text { bridges }\end{array}$ & \\
\hline 6. & Pemakaian gigi tiruan & \\
\hline 7. & Pencabutan gigi & \\
\hline 8. & Penambalan gigi & \\
\hline 9. & Perawatan saluran akar & \\
\hline
\end{tabular}

Data penelitian dianalisis menggunakan distribusi frekuensi dari jawaban kuesioner sesuai dengan Fonseca's anamnestic index. Variabel penelitian dianalisis menggunakan uji chi-square untuk mengetahui adanya perbedaan bermakna antara jenis kelamin, usia, serta riwayat medis dan riwayat perawatan gigi dan mulut dengan tingkat keparahan TMD. Tingkat signifikansi ditetapkan sebesar $5 \%$.

Tabel 3. Klasifikasi tingkat keparahan $\mathrm{TMD}^{8}$

\begin{tabular}{clc}
\hline No. & Klasifikasi & Total poin \\
\hline 1. & Tanpa TMD & $0-15$ \\
2. & TMD ringan & $20-40$ \\
3. & TMD sedang & $45-65$ \\
4. & TMD berat & $70-100$ \\
\hline
\end{tabular}

\section{HASIL PENELITIAN}

Pengambilan data yang dilakukan pada lansia penghuni tetap Panti Wreda Pucang Gading Kota Semarang melalui izin dari KEPK FK Undip No. 233/EC/KEPK/FKUNDIP/X/2020 dan informed consent yang ditandatangani oleh responden. Jumlah responden sebanyak 57 orang terdiri dari 23 laki-laki (40\%) dan 34 perempuan $(60 \%)$. Tabel 4 memperlihatkan karakteristik responden berdasarkan usia.

Tabel 4. Data responden berdasarkan usia

\begin{tabular}{ccc}
\hline $\begin{array}{c}\text { Usia } \\
\text { (tahun) }\end{array}$ & $\mathbf{N}$ & $\mathbf{\%}$ \\
\hline $60-69$ & 20 & 35 \\
$70-79$ & 27 & 47 \\
$>80$ & 10 & 18 \\
Total & 57 & 100 \\
\hline
\end{tabular}

Berdasarkan total skor jawaban FQ yang telah diklasifikasikan menurut tingkat keparahan TMD, didapatkan 17 orang (30\%) dikategorikan tanpa TMD, 18 orang (32\%) mengalami TMD ringan, 12 orang (21\%) mengalami TMD sedang, dan 10 orang (17\%) mengalami TMD berat (Gambar 1).

Distribusi tingkat keparahan TMD berdasarkan jenis kelamin dan usia ditampilkan pada Gambar 2 dan 3, serta riwayat medis dan riwayat perawatan gigi dan mulut ditampilkan pada Tabel 5.

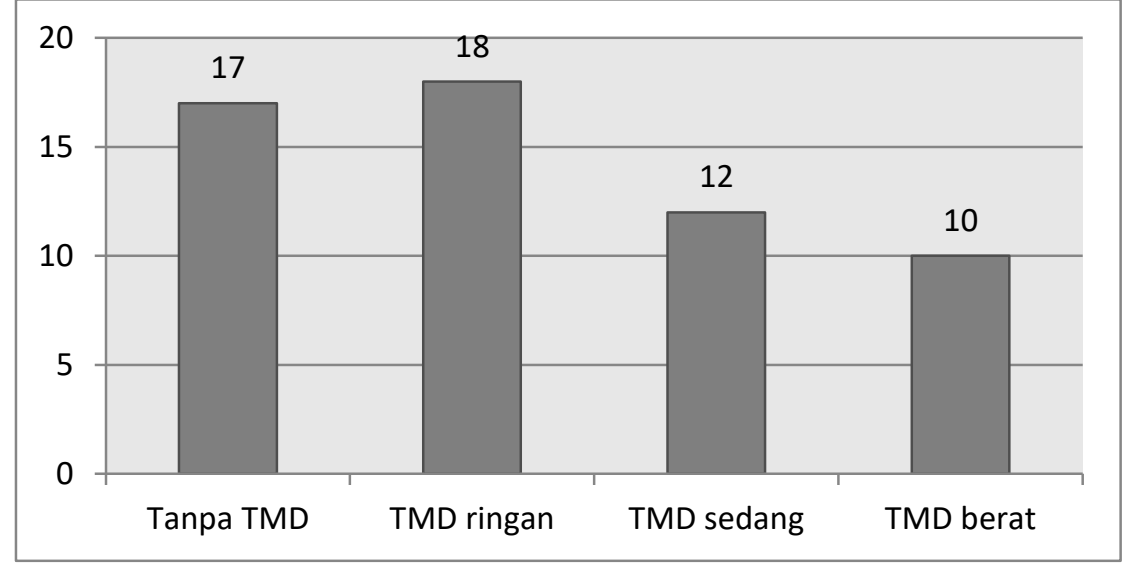

Gambar 1. Distribusi tingkat keparahan TMD 




Gambar 2. Distribusi tingkat keparahan TMD berdasarkan jenis kelamin

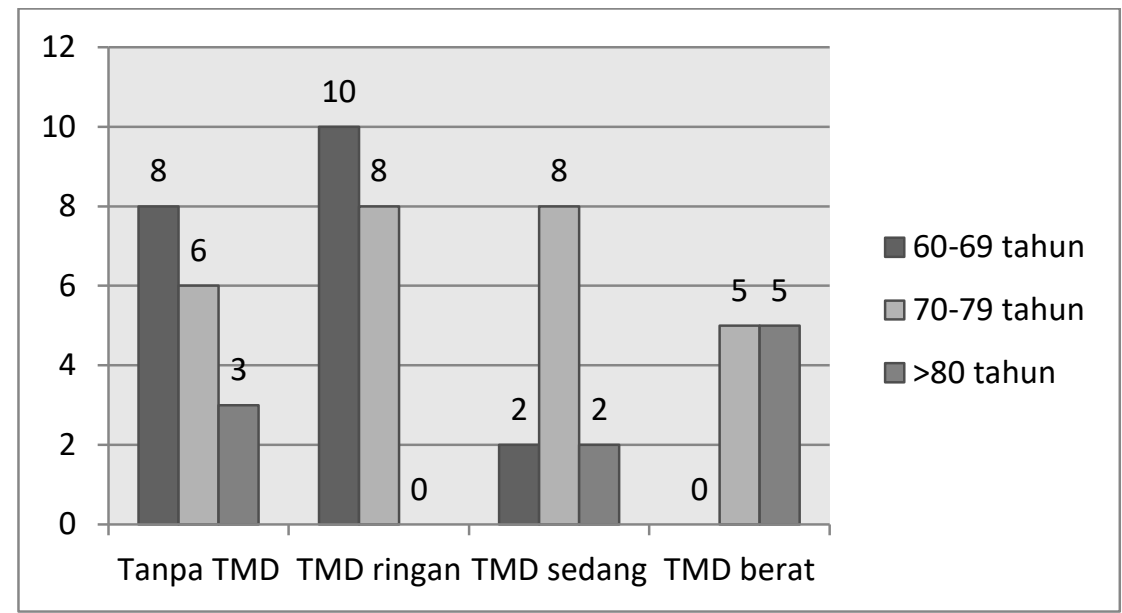

Gambar 3. Distribusi tingkat keparahan TMD berdasarkan usia

Tabel 5. Distribusi tingkat keparahan TMD berdasarkan riwayat medis dan riwayat perawatan gigi mulut

\begin{tabular}{lcccc}
\hline $\begin{array}{l}\text { Riwayat medis dan riwayat perawatan gigi } \\
\text { dan mulut }\end{array}$ & $\begin{array}{c}\text { Tanpa } \\
\text { TMD }\end{array}$ & $\begin{array}{c}\text { TMD } \\
\text { ringan }\end{array}$ & $\begin{array}{c}\text { TMD } \\
\text { sedang }\end{array}$ & $\begin{array}{c}\text { TMD } \\
\text { berat }\end{array}$ \\
\hline $\begin{array}{l}\text { Artritis N=43 (75\%) } \\
\text { Gangguan muskuloskeletal di area kepala }\end{array}$ & 10 & 14 & 10 & 9 \\
dan leher N=53 (93\%) & 16 & 16 & 11 & 10 \\
Gangguan stres emosional N=48 (84\%) & 12 & 15 & 12 & 9 \\
Perawatan ortodontik N=5 (9\%) & 0 & 3 & 2 & 0 \\
Pemasangan crown and brigde & 6 & 5 & 2 & 0 \\
N=13 (23\%) & 15 & 9 & 4 & 5 \\
Memakai gigi tiruan N=33 (58\%) & 17 & 18 & 9 & 8 \\
Pencabutan gigi N=52 (91\%) & 0 & 6 & 4 & 3 \\
Penambalan gigi N=13 (23\%) & 0 & 3 & 2 & 1 \\
Perawatan saluran akar N 6 (11\%) & & & & \\
\hline
\end{tabular}


Tabel 6. Hasil analisis uji chi-square

\begin{tabular}{lc}
\hline & Tingkat keparahan \\
& TMD \\
& Nilai p \\
\hline Jenis kelamin & 0,510 \\
Usia & $\mathbf{0 , 0 0 6}$ \\
Artritis & 0,247 \\
Gangguan muskuloskeletal di & 0,733 \\
area kepala dan leher & \\
Gangguan stres emosional & 0,180 \\
Perawatan ortodontik & 0,177 \\
Pemasangan crown and bridge & 0,174 \\
Memakai gigi tiruan & $\mathbf{0 , 0 1 8}$ \\
Pencabutan gigi & $\mathbf{0 , 0 3 1}$ \\
Penambalan gigi & 0,066 \\
Perawatan saluran akar & 0,361 \\
\hline
\end{tabular}

Tabel 6 memperlihatkan hasil analisis uji chi-square terhadap variabel penelitian dan tingkat keparahan TMD. Nilai $p<0,05$ diperoleh pada tiga variabel, yaitu usia, memakai gigi tiruan, dan pencabutan gigi.

\section{BAHASAN}

Pada penelitian ini terdapat 57 responden; jenis kelamin perempuan lebih dominan daripada laki-laki, yaitu sebanyak 34 orang $(60 \%)$. Hal ini disebabkan lansia lakilaki yang menetap di panti lebih sedikit jumlahnya dan yang masuk ke dalam kriteria inklusi hanya sebanyak 24 orang (40\%). Hasil penelitian ini sejalan dengan penelitian oleh Maqhfirah ${ }^{2}$ dan Himawan et $\mathrm{al}^{3}$ yang mendapatkan responden lansia perempuan lebih banyak daripada lansia laki-laki.

Lansia yang menjadi responden ini masih mampu berkomunikasi dengan baik dan dalam kondisi fisik yang sehat sehingga dapat melakukan pengisian informed consent dan kuesioner secara mandiri. Rentang usia lansia yang paling banyak ditemukan yaitu usia 70-79 tahun (47\%), diikuti usia 60-69 tahun (35\%), dan usia di atas 80 tahun (18\%). Hasil penelitian ini sejalan dengan penelitian oleh Khasanah dan Priyanto ${ }^{4}$ dan Gabrila et $\mathrm{al}^{1}$ yang mendapatkan lansia berusia 70 tahun lebih dominan dalam kedua penelitian tersebut.

Frekuensi distribusi data yang diperoleh menunjukkan bahwa lansia berjenis kelamin perempuan lebih banyak mengalami TMD, baik derajat ringan hingga berat. Hasil ini sesuai dengan penelitian oleh Bagis et $\mathrm{al}^{8}$ yang menyebutkan bahwa tingkat keparahan TMD lebih bermakna pada perempuan dan bunyi clicking ditemukan empat kali lebih banyak pada perempuan daripada laki-laki. Perbedaan tingkat keparahan TMD sering dikaitkan dengan menopause yang memiliki hubungan antara degenerasi TMJ dengan menurunnya kadar hormon esterogen pada perempuan. Penurunan kadar esterogen pada perempuan yang telah menopause dapat menyebabkan penurunan fleksibilitas dan integritas pada fibrokartilago kondilus mandibula sehingga akan meningkatkan degenerasi TMJ. ${ }^{9}$ Hasil penelitian ini agak berbeda dengan penelitian prevalensi TMD pada lansia di Vietnam oleh Nguyen et al ${ }^{10}$ yang menyatakan bahwa tidak terdapat perbedaan bermakna dalam jenis kelamin. Pada penelitian ini, hasil analisis statistik menunjukkan tidak terdapat perbedaan bermakna antara tingkat keparahan TMD dengan jenis kelamin pada lansia $(\mathrm{p}=0,510)$.

Berdasarkan usia, pada penelitian ini didapatkan persentase lansia yang mengalami TMD paling banyak pada usia 70-79 tahun. Berdasarkan tingkat keparahan TMD, diperoleh bahwa lansia dengan kategori tanpa TMD dan TMD ringan paling banyak terdapat pada rentang usia 60-69 tahun; kategori TMD sedang paling banyak terdapat pada rentang usia 70-79 tahun; dan kategori TMD berat paling banyak ditemukan pada lansia berusia 70-79 tahun dan usia 80 tahun ke atas. Selain itu, hasil uji chisquare pada penelitian ini memperlihatkan nilai $\mathrm{p}=0,006(<0,05)$ untuk variabel usia terhadap tingkat keparahan TMD. Hasil penelitian ini selaras dengan penelitian oleh Maqhfirah $^{2}$ yang menyatakan bahwa lansia pada kelompok usia 91-100 tahun memiliki prevalensi TMD paling berat dan kelompok usia 60-70 tahun memiliki prevalensi TMD yang paling ringan. Hal ini berkaitan dengan struktur dan fungsi TMJ yang akan menurun seiring bertambahnya usia, sehingga derajat keparahan TMD semakin tinggi. ${ }^{9,11}$

Faktor stres psikologi dan jumlah 
kehilangan gigi yang cenderung meningkat seiring bertambahnya usia juga menjadi faktor predisposisi tingkat keparahan TMD yang semakin tinggi. ${ }^{12-13}$ Hasil analisis statistik memperlihatkan adanya perbedaan bermakna tingkat keparahan TMD terhadap kelompok usia lansia. Peningkatan stres diyakini dapat menyebabkan kebiasaan buruk seperti bruxism dan clenching, sehingga menyebabkan penggunaan otot secara berlebihan dan dapat berakibat timbulnya nyeri pada TMJ. ${ }^{14}$

Pada penelitian ini, terdapat sebanyak 43 lansia (75\%) memiliki riwayat artritis, 53 lansia (93\%) memiliki riwayat gangguan muskuloskeletal di area kepala dan leher, serta 48 lansia (84\%) memiliki riwayat stres emosional. Dari jumlah tersebut, sebagian besar berada pada klasifikasi TMD ringan hingga berat. Hasil penelitian ini sesuai dengan penelitian oleh Habib et $\mathrm{al}^{12}$ yang mencatat bahwa hampir sepertiga dari subjek penelitian memiliki riwayat stres emosional, dan dari $57,8 \%$ di antaranya diklasifikasikan mengalami derajat TMD ringan hingga berat. Hasil penelitian oleh Nguyen et al ${ }^{10}$ juga menyebutkan nyeri pada otot pengunyahan ditemukan pada $25,6 \%$ lansia di Vietnam, dan menjadi salah satu faktor predisposisi terhadap tingkat keparahan TMD.

Perubahan pada oklusi yang disebabkan oleh perawatan gigi seperti pencabutan gigi, pemakaian gigi tiruan, penambalan gigi, pemasangan crown dan bridge, perawatan saluran akar, serta perawatan ortodontik dapat menimbulkan terjadinya TMD apabila terjadi kesalahan dalam penetapan oklusi yang tidak sesuai. Setiap kesalahan pada penentuan oklusi yang disebabkan oleh perawatan gigi menyebabkan peningkatan ketegangan otot dan nyeri pada TMJ sehingga menyebabkan keluhan TMD ringan. Hasil uji chi-square pada penelitian ini memperlihatkan perbedaan bermakna dari keparahan TMD pada responden yang memakai gigi tiruan dan pencabutan gigi $(p<0,05)$. Hasil penelitian oleh Habib et $a^{12}$ melaporkan hampir seperempat dari subjek yang diklasifikasikan ke dalam kategori TMD sedang dan berat, memiliki riwayat perawatan gigi sebelumnya.

Riwayat perawatan gigi yang paling sering ditemukan pada penelitian ini ialah pencabutan gigi (91\%). Hasil ini sesuai dengan survei Badan Pusat Statistik (BPS) pada tahun 2014 yang mengemukakan bahwa angka kehilangan gigi banyak ditemukan di Indonesia pada lansia berusia 65 tahun ke atas, yaitu sebesar 24\%. Kehilangan gigi merupakan masalah yang dapat berpengaruh pada fungsi pengunyahan dan TMJ. Hal ini bisa berdampak pada tingkat keparahan TMD karena hilangnya gigi akibat pencabutan akan mengakibatkan gigi yang masih tersisa di rongga mulut menerima beban yang lebih besar dari sebelumnya. ${ }^{15}$ Penelitian oleh Agtini ${ }^{16}$ mencatat bahwa kehilangan gigi dapat menimbulkan terjadinya clicking sehingga menyebabkan TMD.

Riwayat pemakaian gigi tiruan juga ditemukan pada subjek penelitian, dan $45 \%$ di antaranya masuk dalam kategori tanpa TMD. Gigi tiruan mampu mengurangi keluhan terkait TMD, karena dapat mengembalikan oklusi yang tidak sesuai akibat gigi yang hilang. Hasil ini sesuai dengan penelitian oleh Hiltunen ${ }^{17}$ terhadap lansia yang hidup mandiri di rumah. Sebanyak $70 \%$ dari lansia tersebut mengeluhkan adanya ketidaksesuaian pada oklusi jika tidak memakai gigi tiruan. Namun apabila gigi tiruan dipasang hanya sebanyak $4 \%$ yang tidak memiliki kontak oklusi antara rahang antagonisnya.

\section{SIMPULAN}

Tingkat keparahan TMD akan meningkat seiring bertambahnya usia. Perawatan medis, gigi, dan mulut yang optimal dapat berpengaruh terhadap terjadinya TMD pada lansia.

\section{Konflik Kepentingan}

Penulis menyatakan tidak terdapat konflik kepentingan dalam penelitian ini.

\section{DAFTAR PUSTAKA}

1. Gabrila J, Tendean L, Zuliari K. Gambaran temporomandibular disorder pada lansia di Kecamatan Wanea. e-GiGi. 2016; 
4(2):90-5.

2. Maqhfirah A. Prevalensi kelainan sendi temporomandibular pada lanjut usia di Panti Jompo Tresna Werdah Gau Mabaji Kabupaten Gowa [Skripsi]. Makassar: Universitas Hasanuddin; 2010.

3. Himawan LS, Kusdhany LS, Ariani N. Temporomandibular disorders in elderly patients. Med J Indones. 2007;16(4):237-9.

4. Khasanah AIKL, Priyanto D. Pengaruh gangguan sendi temporomandibula terhadap kualitas hidup terkait kesehatan gigi dan mulut pada lansia. Jurnal PDGI. 2012; 61(3):102-9.

5. José G, Paula V, Ricardo de L, Ana C, Marcio R, Luciana L, Karen B. Signs and symptoms of temporomandibular disorders in the elderly. Universidade Norte do Parana, Brazil. CoDAS. 2014;26(1):76-80.

6. Nomura K, Vitti M, de Oliveira AS, Chaves TC, Semprini M, siéssere $S$, et al. Use the fonseca's questionnaire to assess the prevalence and severity of temporomandibular disorders in Brazilian Dental Undergraduates. Braz Dent J. 2017;18(2):163-7.

7. Laplanche O, Ehrmann E, Pedeutour P, Duminil G. TMD clinical diagnostic classification (temporomandibular disorder). J Dentfacial Anom Orthod. 2012; 15(202):1-3.

8. Bagis B, Ayaz EA, Turgut S, Durkan R, Özcan $\mathrm{M}$. Gender difference in revalence of signs and symptoms of temporomandibular joint disorders: a retrospective study on 243 consecutive patients. Intl journal of med science. 2012;9(7):539-44.

9. Yadav S, Yang Y, Dutra EH, Robinson JL,
Wadhwa S. Temporomandibular joint disorders in the elderly and aging population. J Am Geriatr Soc. 2018; 66(6):1213-7.

10. Nguyen MS, Jagomägi T, Nguyen T, Saag M, Voog-Oras Ü. Symptoms and signs of temporomandibular disorders among elderly Vietnamese. Proc Singapore Healthc. 2017;26(4):211-6.

11. Guarda-Nardini L, Piccotti F, Mogno G, Favero L, Manfredini D. Age-related differences in temporomandibular disorder diagnoses. Cranio. 2012;30:103-9.

12. Habib SR, Al Rifaiy MQ, Awan KH, Alsaif A, Alshalan A, Altokais Y. Prevalence and severity of temporomandibular disorders among university students in Riyadh. Saudi Dent J. 2015;27(3):125-30.

13. Komiyama O, Obara R, lida T, Nishimura H, Okubo M, Uchida T, et al. Age-related associations between psychological characteristics and pain intensity among Japanese patients with temporomandibular disorder. J Oral Sci. 2014; 56:221-5.

14. Hedge V. A review of the disorders of temporomandibular joint. $\mathrm{J}$ Indian Prosthodontic Soc .2005;5:56-61.

15. Gupta S, Gupta R, Rajeev Garg. Partial edentulism and temporomandibular joint disorders. IOSR-JDMS. 2014; 13(12):60-3.

16. Agtini D. Persentase pengguna protesa di Indonesia. Media Litbang Kesehatan 2010;20(2):50-8.

17. Hiltunen K. Temporomandibular disorders in the elderly: A 5-year follow-up of signs and symptoms of TMD [Academic dissertation]. Helsinki: University of Helsinki; 2004. 